\title{
PERBANDINGAN ELMAN RECURRENT NEURAL NETWORKS, BACKPROPAGATION NEURAL NETWORKS, DAN EXPONENTIAL SMOOTHING DALAM PERAMALAN PRODUKSI PALAWIJA
}

\author{
Winda Aprianti*1 ${ }^{1}$ Jaka Permadi $^{2}$ Herfia Rhomadhona $^{3}$ \\ 1, 2, 3 Jurusan Teknik Informatika, Politeknik Negeri Tanah Laut \\ winda@politala.ac.id*11, jakapermadi.88@politala.ac.id², \\ herfia.rhomadhona@politala.ac.id ${ }^{3}$ \\ *Corresponding Author
}

Received 20 October 2020; revised 15 December 2020; accepted 24 December 2020.

\begin{abstract}
ABSTRAK
Jumlah produksi tanaman palawija di Kabupaten Tanah Laut yang fluktuatif berdampak pada jumlah persediaan pangan. Jika terjadi penurunan jumlah produksi tanaman palawija dibanding tahun sebelumnya, maka pemerintah sebagai pemangku kepentingan harus mempunyai rencana untuk menghadapi keadaan ini. Hal ini dapat dilakukan apabila pemerintah mempunyai hasil prediksi produksi tanaman palawija. Hasil peramalan yang tepat dapat dihasilkan dengan memilih metode yang tepat pula. Penelitian ini menggunakan tiga metode untuk meramalkan produksi tanaman palawija, yakni Elman Recurrent Neural Network (ERNN), Backpropagation Neural Network (BPNN), dan Exponential Smoothing (ES). Mean Absolute Percentage Error (MAPE) digunakan untuk mengetahui performa terbaik dari ketiga metode peramalan tersebut. Visual Basic digunakan sebagai alat bantu untuk menjalankan program dan perhitungan MAPE. Penelitian ini menghasilkan bahwa MAPE untuk ERNN berada pada rentang 0.0151 sampai dengan 3.3610, BPNN pada rentang 0.0896 sampai dengan 3638.0264, ES pada rentang 0.4987 sampai dengan 44357.4931. ERNN menghasilkan MAPE terkecil untuk dataset jagung, kacang hijau, kacang tanah, kedelai, padi, dan ubi kayu. Sedangkan BPNN menghasilkan MAPE terkecil untuk dataset ubi jalar. Oleh karena itu, ERNN merupakan metode dengan performa terbaik karena MAPE yang dihasilkan terkecil untuk enam dari tujuh dataset.
\end{abstract}

Kata kunci: BPNN, ERNN, ES, MAPE, peramalan.

\section{ABSTRACT}

The fluctuating amount of palawija crop production in Tanah Laut Regency has an impact on the amount of food supply. If there is a decrease in the number of secondary crop production compared to the previous year, then the government as a stakeholder must have a plan to deal with 
this situation. This can be done if the government has a predictive result of crop production. Precise forecasting results can be generated by choosing the right method as well. This study uses three methods to predict crop production of crops, namely the Elman Recurrent Neural Network (ERNN), Backpropagation Neural Network (BPNN), and Exponential Smoothing (ES). Mean Absolute Percentage Error (MAPE) is used to determine the best performance of the three forecasting methods. Visual Basic is used as a tool for running MAPE programs and calculations. This research shows that MAPE for ERNN is in the range 0.0151 to 3.3610, BPNN is in the range 0.0896 to 3638.0264 , ES in the range 0.4987 to 44357.4931 . ERNN produced the smallest MAPE for the corn, mung bean, peanut, soybean, rice, and cassava dataset. Meanwhile, BPNN produced the smallest MAPE for the sweet potato dataset. Therefore, ERNN is the best performing method because the MAPE generated is the smallest for six of the seven datasets.

Keywords: BPNN, ERNN, ES, MAPE, forecasting.

\section{PENDAHULUAN}

Pertanian merupakan salah satu sector utama dalam perekonomian dan sebagai mata pencaharian masyarakat kabupaten Tanah Laut. Berdasarkan warta berita aktual kalsel menyatakan bahwa 67\% warga kabupaten Tanah Laut bekerja di sektor pertanian dan hortikultura. Hal ini didukung dengan sumber daya lahan yang luas dan iklim yang sesuai. Penggunaan lahan Kabupaten Tanah Laut didominasi oleh lahan pertanian dan perkebunan yaitu seluas 349.973 Ha, dengan kondisi lahan pertanian berupa lahan yang berpetak-petak dan dibatasi oleh pematang (galengan), saluran untuk menahan/menyalurkan air untuk tanaman padi sawah.

Berdasarkan fakta mengenai lahan pertanian di Kabupaten Tanah Laut dan data dari BPS (2017) diketahui bahwa komoditi pertanian yang dihasilkan berupa perkebunan palawija antara lain jagung, kedelai, kacang tanah, kacang hijau, ubi kayu, dan ubi jalar. Jumlah komoditi pertanian tersebut mengalami jumlah fluaktuasi yang mana setiap tahun jumlah komoditi selalu berubah-ubah. Khususnya pada tanaman jagung mengalami penurunan yang signifikan pada tahun 2017. Hal ini menjadi perhatian yang sangat besar bagi pemerintah dan masyarakat untuk mencari solusi karena kurangnya informasi mengenai dampak alih fungsi lahan pertanian yang mempengaruhi hasil produksi sehingga kebutuhan pangan tidak terpenuhi.

Untuk mengetahui jumlah komoditi hasil pertanian dapat dilakukan sebuah peramalan. Peramalan tersebut bertujuan sebagai salah satu unsur yang sangat 
penting dalam pengambilan keputusan agar menghasilkan data yang akurat. Peramalan merupakan suatu kegiatan untuk memprediksi kejadian di masa yang akan datang dengan menggunakan dan mempertimbangkan data dari masa lampau (Safitri, Dwidayati, dan Sugiman, 2017). Terdapat beberapa metode yang dapat digunakan untuk peramalan antara lain exponential smoothing (ES) dan metode neural network seperti Elman Recurrent Neural Networks (ERNN), Backpropagation Neural Networks (BPNN).

Exponential smoothing merupakan metode yang paling sering digunakan dalam meramalkan masa yang akan datang, karena dalam proses peramalan metode ini menghasilkan data ramalan dengan nilai kesalahan yang sangat kecil. Seperti penelitian yang dilakukan oleh Apriliyani, Permadi dan Rhomadhona (2018) menggunakan exponential smoothing dengan teknik Mean Absolute Percentage Error (MAPE) untuk menghitung persentase tingkat kesalahan hasil peramalan. Hasil peramalan jumlah siswa sekolah dasar di Kabupaten Tanah Laut pada tahun 2018 berjumlah 35655 siswa, dengan nilai MAPE sebesar 0.770\%, nilai $\alpha=0.77$ dan nilai $\beta=0.8$.

Seiring perkembangan teknologi, beberapa peneliti mencoba melakukan prediksi atau peramalan menggunakan jaringan syaraf tiruan (neural network). Jaringan syaraf tiruan merupakan metode yang meniru cara kerja otak manusia dimana menghubungkan beberapa jumlah sel saraf yang terdiri dari Axon, dendrite synapse agar dapat memberikan solusi terhadap suatu permasalahan (Salman dan Prasetio, 2011). Penelitian menggunakan ERNN pernah dilakukan oleh Afrianty, et al (2018) untuk memprediksi penjualan Pilus agar dapat menimalisir terjadinya kerugian. Parameter yang digunakan yaitu epoch 500, nilai learning rate 0.1 hingga 0.9 dengan arsitektur 5 neuron layer masukan, 7 neurons layer tersembunyi dan 1 output. Berdasarkan pengujian diperoleh akurasi sekitar 90.25\% dengan epoch 500 dan nilai learning rate 0.9. Selain itu, Radjabaycolle dan Pulungan (2016) juga menerapkan metode ERNN untuk memprediksi penggunaan bandwidth. Hasil penelitian dengan menggunakan 13 neuron pada layer tersembunyi diperoleh nilai MSE paling kecil sebesar 0.003725. Sehingga, Suryani dan Wahono (2015) mencoba mengkolaborasikan metode ES dengan neural network guna meningkatkan akurasi neural network untuk memprediksi harga emas. Penelitian tersebut membandingkan nilai RMSE 
yang dihasilkan dari metode Neural Network dan ES dengan fungsi aktivasi binary sigmoid adalah 0.003 .

Selain elman, metode turunan dari JST yang kerap digunakan untuk peramalan adalah BPNN. Seperti yang dilakukan oleh Wong (2019) memprediksi tingkat inflasi di Kota Samarinda dengan metode BPNN dengan parameter seperti fungsi pembelajaran, fungsi aktivasi dan learning rate 0.1 mampu menghasilkan prediksi yang cukup baik dengan nilai MSE sebesar 0.00000424.

Zhang, et al (2013) telah melakukan penelitian guna mengetahui performa dari metode BPNN, Radial Basis Function Neural Network (RBFNN), ERNN, dan Seasonal Autoregressive Integrated Moving Average (SARIMA) untuk memprediksi demam tifoid berdasarkan nilai Mean Absolute Error (MAE), Mean Absolute Percentage Error (MAPE), dan Mean Square Error (MSE). Hasil penelitian menunjukkan metode dengan performa yang lebih baik secara berturutturut adalah RBFNN, ERNN, BPNN, dan SARIMA.

Berdasarkan beberapa penjelasan tersebut diperlukan analisis lebih mendalam pada metode ES, ERNN dan BPNN di bidang peramalan komoditi pertanian khususnya palawija. Pada penelitian ini mengimplementasikan ketiga metode tersebut menggunakan bahasa pemrograman visual studio. Perbandingan in dilakukan untuk mengetahui besarnya tingkat keakuratan atau akurasi dari hasil ramalan dengan melihat nilai MAPE yang dihasilkan dari masing-masing metode.

\section{METODE PENELITIAN}

Tahapan pengerjaan penelitian ini diuraikan sebagai berikut.

1. Mengumpulkan Data

Pada tahap ini dilakukan pengumpulan data jumlah produksi palawija di Kalimantan Selatan pada tahun 1993 sampai dengan tahun 2015 dari kaggle.com, kemudian dibagi menjadi 80\% data latih dan 20\% data uji.

2. Menerapkan metode Elman Recurrent Neural Networks (ERNN), Backpropagation Neural Networks (BPNN), dan Exponential Smoothing (ES) Pada tahap ini akan diterapkan metode ERNN, BPNN, dan ES dengan learning rate 0.1 sampai dengan 0.9 untuk memprediksi jumlah produksi ketujuh data. Penerapan metode dilakukan dengan membuat source code yang sesuai dengan alur metode menggunakan Visual Basic. Rumus setiap metode yang digunakan untuk source code sebagai berikut.

i. Elman Recurrent Neural Networks (ERNN) 
ERNN dihitung menggunakan Persamaan 1 sampai dengan Persamaan 3.

$$
\begin{gathered}
y(k)=g\left(\omega_{3} x(k)\right) \\
x(k)=f\left(\omega_{1} x_{c}(k)+\omega_{2}(u(k-1))\right) \\
x_{c}(k)=x(k-1)
\end{gathered}
$$

dengan

$u(k-1)=$ Input dari network

$y(k) \quad=\quad$ Output dari network

$x_{c}(k)=$ Node dari layer konteks

$x(k) \quad=\quad$ Node dari layer tersembunyi

$\omega_{1}, \omega_{2}, \omega_{3}=$ Bobot untuk layer konteks, input, dan output tersembunyi

ii. Backpropagation Neural Networks (BPNN)

Output dari semua node hidden layer dihitung menggunakan Persamaan 4 sampai dengan Persamaan 6.

$$
\begin{aligned}
\text { net }_{j} & =\sum_{i=0}^{n} \omega_{i j} x_{i} \\
y_{j} & =f\left(\text { net }_{j}\right) \\
f(x) & =\frac{1}{1+\exp (-x)}
\end{aligned}
$$

dengan

$$
\begin{array}{ll}
\text { net }_{j} & =\text { Nilai aktivasi dari node ke- } j \\
\omega_{i j} & =\text { Bobot penghubung dari node inputan } i \text { ke node tersembunyi } j \\
x_{i} & =\text { Inputan ke- } i \\
y_{j} & =\text { Output dari node ke-j pada layer tersembunyi } \\
f & =\text { fungsi sigmoid yang merupakan fungsi aktivasi }
\end{array}
$$

iii. Exponential Smoothing (ES)

Abraham dan Ledolter (2005) menyebutkan bahwa metode ES menggunakan bobot rata-rata dari nilai time series sebelumnya untuk peramalan yang disajikan pada Persamaan7.

$$
F_{t+1}=\alpha Y_{t}+(1-\alpha) F_{t}
$$

dengan

$F_{t+1}=$ Nilai peramalan untuk waktu $t+1$

$Y_{t} \quad=$ Nilai sebenarnya untuk waktu $t$

$F_{t} \quad=$ Nilai peramalan untuk waktu $t$

$\alpha=$ Konstanta pemulusan $(0<\alpha<1)$

3. Menghitung Mean Absolute Percentage Error (MAPE) 
Jika diketahui $n$ adalah banyaknya iterasi yang terjadi, $Y_{t}$ adalah nilai sebenarnya pada waktu $t$, dan $F_{t}$ adalah nilai peramalan pada waktu $t$ maka MAPE dihitung menggunakan Persamaan 8.

$$
M A P E=\frac{1}{n} \sum_{t=1}^{n}\left|\frac{Y_{t}-F_{t}}{Y_{t}}\right|
$$

4. Menganalisis hasil MAPE antar metode dalam setiap dataset

Pada tahap ini akan dilakuk ananalisis terhadap hasil MAPE yang diperoleh pada Langkah 3 untuk mengetahui performa setiap metode.

\section{HASIL PENELITIAN DAN PEMBAHASAN}

Tahapan pertama, yakni pengumpulan data jumlah produksi palawija di Kalimantan Selatan pada tahun 1993 sampai dengan tahun 2015 dari kaggle.com menghasilkan dataset jagung, dataset kacang tanah, dataset kedelai, dataset padi, dataset ubi jalar, dan dataset ubi kayu yang masing-masing terdiri dari 23 data, serta dataset kacang hijau yang terdiri dari 19 data. Tahapan selanjutnya adalah pembuatan program menggunakan Visual Basic. Gambar 1 dan 2 secara berturutturut merupakan penerapan training dan testing untuk metode ERNN.

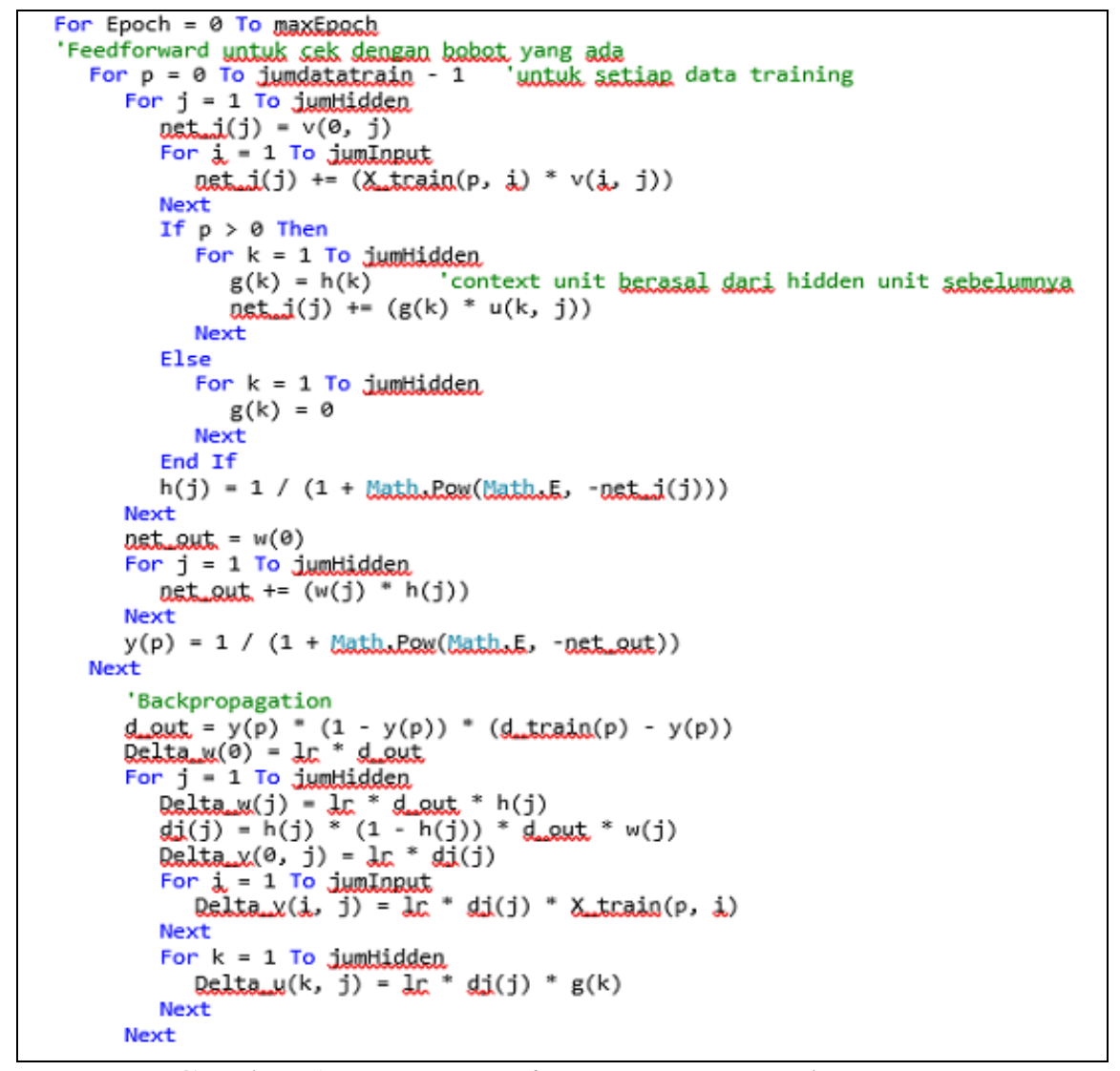

Gambar 1. Source Code Training Metode ERNN 


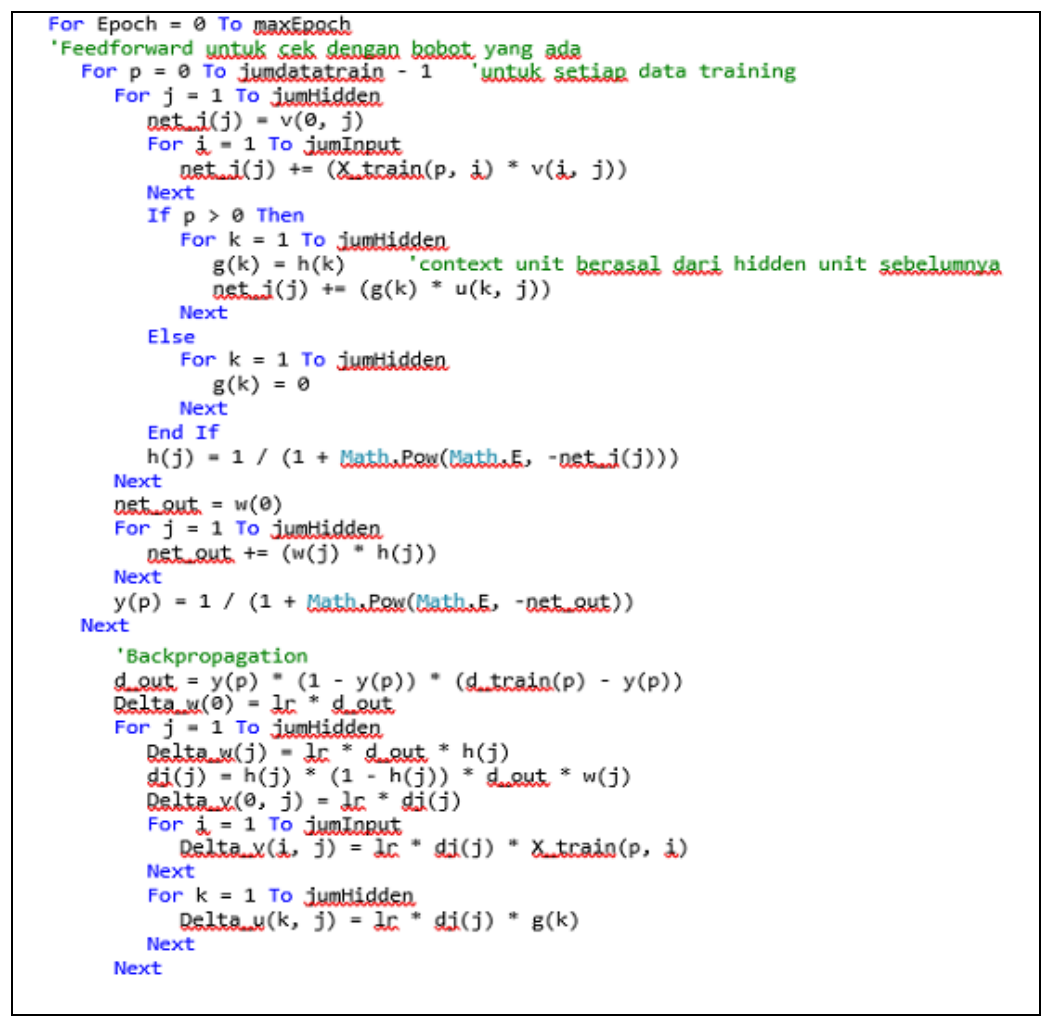

Gambar 2. Source Code Testing Metode ERNN

Gambar 3 dan Gambar 4 secara berturut-turut merupakan penerapan training dan testing untuk metode BPNN.

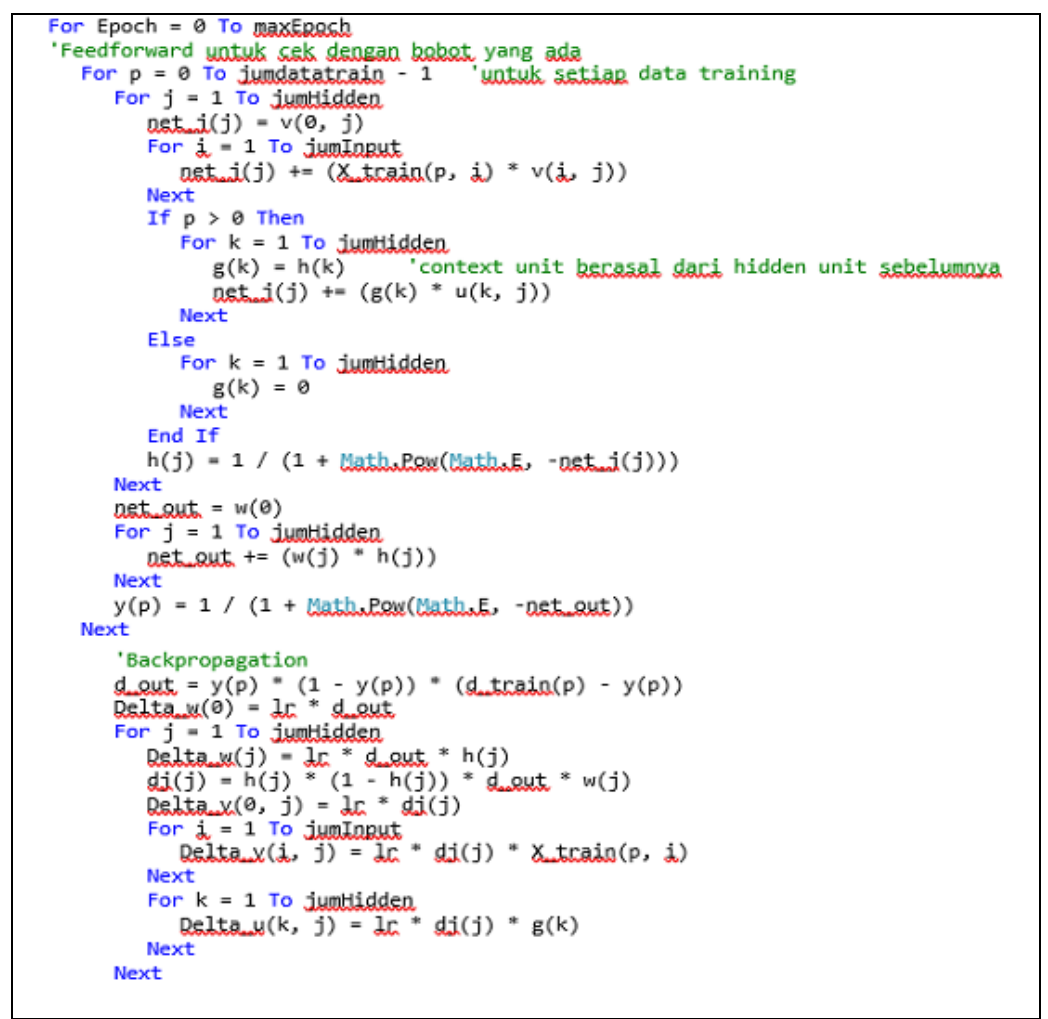

Gambar 3. Source Code Training Metode BPNN 


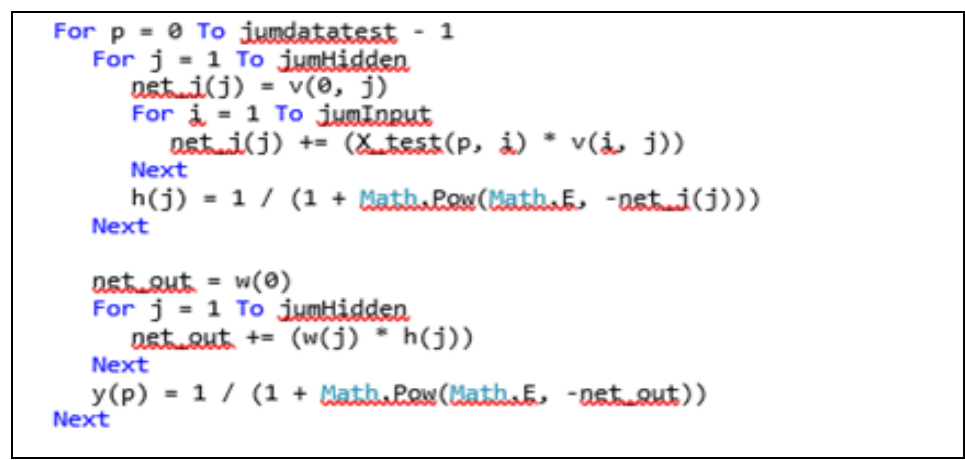

Gambar 4. Source Code Testing Metode BPNN

Gambar 5 merupakan penerapan untuk metode ES.

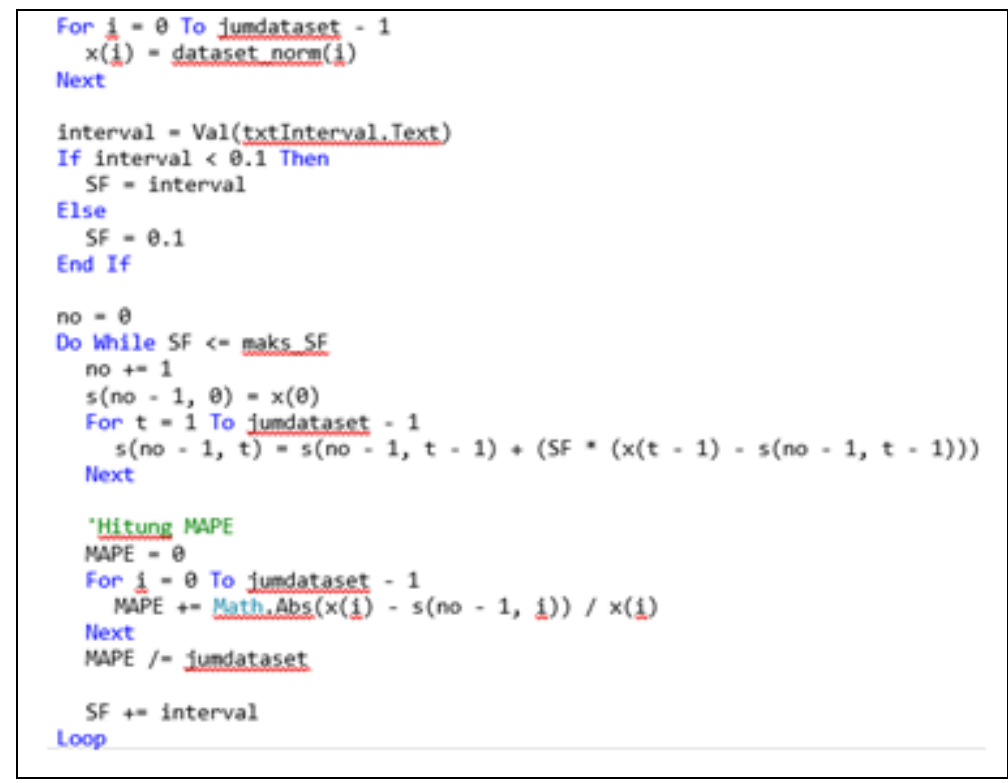

Gambar 5. Source Code Training Metode ES

Kemudian untuk perhitungan MAPE disajikan pada Gambar 6.

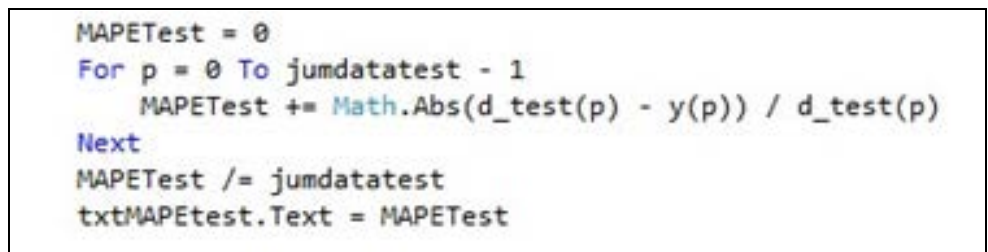

Gambar 6. Source Code untuk MAPE

Program yang telah dibuat dijalankan untuk memilih dataset, metode dan menuliskan learning rate, sebagai contoh untuk dataset jagung, metode yang dipilih ERNN dengan learning rate 0.1 dan mengklik tombol proses maka menghasilkan MAPE seperti yang disajikan Gambar 7 dan Gambar 8. 


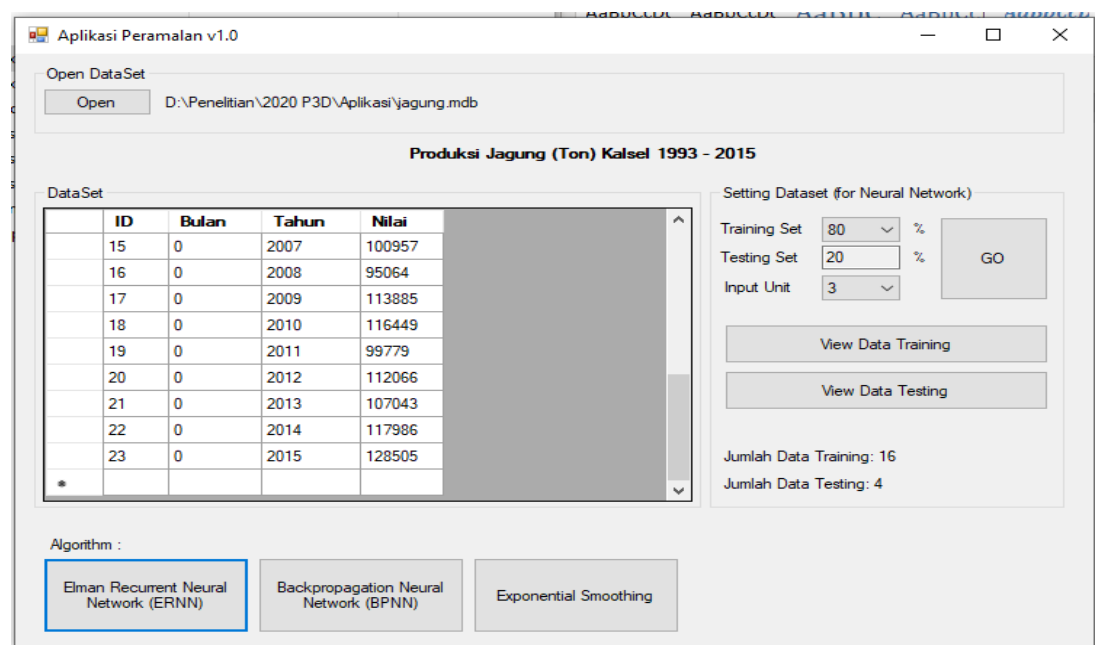

Gambar 7. Tampilan untuk Memilih Dataset dan Metode

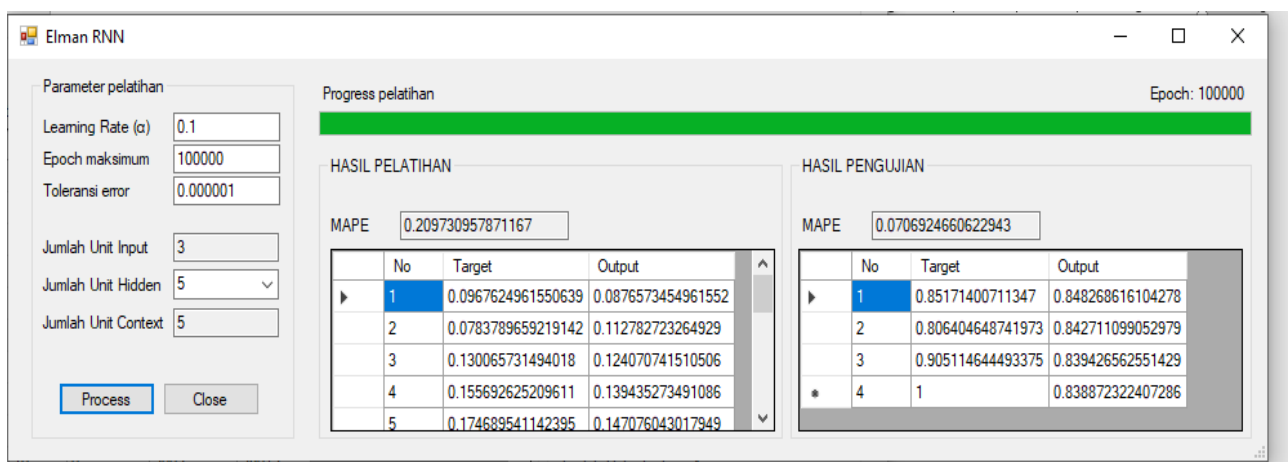

Gambar 8. Tampilan untuk Penulisan Learning Rate dan Hasil MAPE

Program ini dijalankan dengan memilih ketujuh dataset untuk setiap metode dan learning rate 0.1 sampai dengan 0.9 secara bergantian yang menghasilkan MAPE hasil pengujian yang disajikan pada Gambar 9 sampai dengan Gambar 15.

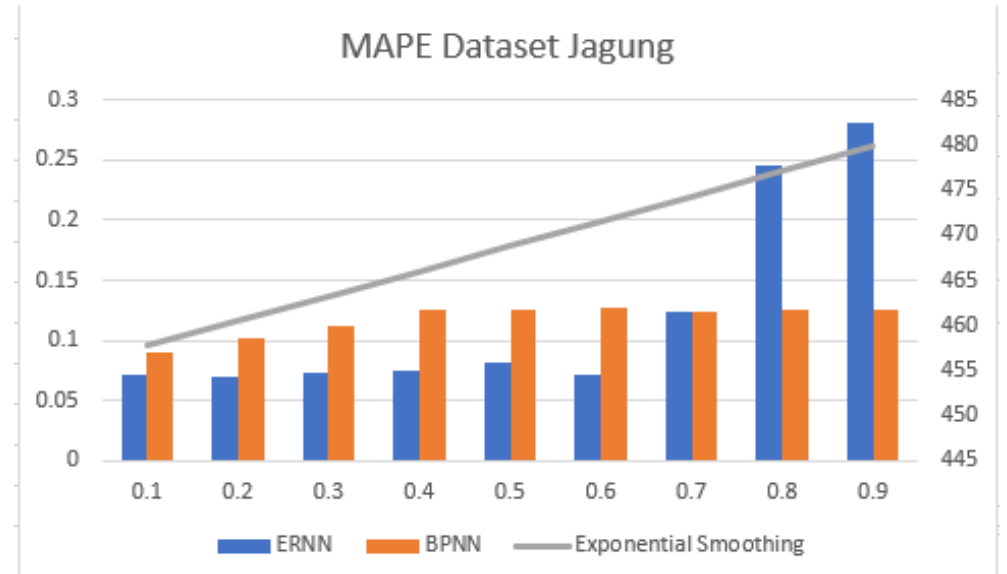

Gambar 9. MAPE untuk Dataset Jagung 
Gambar 9 merupakan hasil MAPE untuk dataset jagung yang menunjukkan bahwa MAPE yang dihasilkan dari penerapan ERNN dan BPNN lebih kecil dibanding ES, dengan MAPE terendah dihasilkan oleh penerapan metode ERNN dengan learning rate 0.6, yakni 0.0693. Sedangkan MAPE paling besar adalah penerapan metode ES yang menghasilkan 480.0027. MAPE untuk ketiga metode menunjukkan peningkatan jika learning rate ditingkatkan.

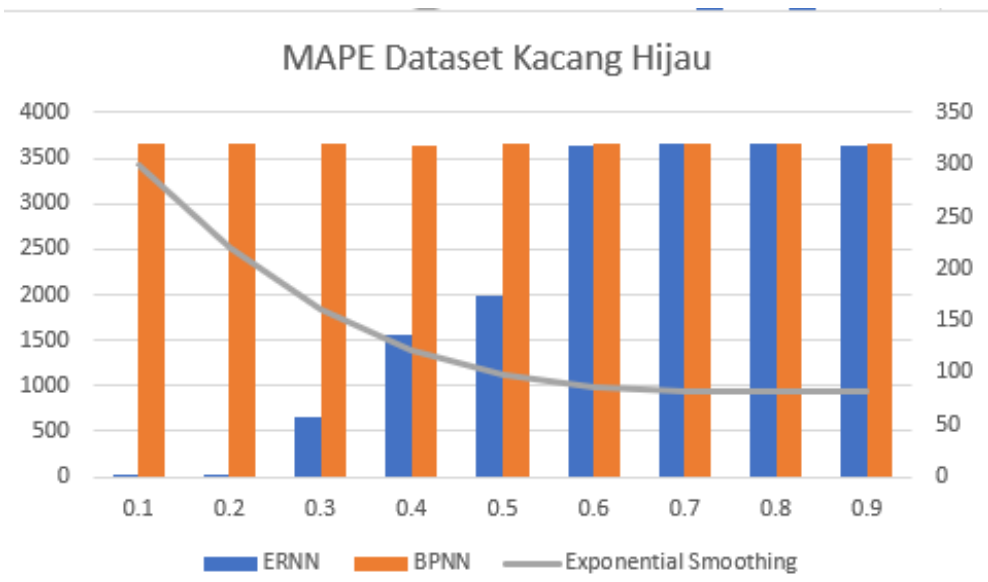

Gambar 10. MAPE untuk Dataset Kacang Hijau

Gambar 10 merupakan hasil MAPE untuk dataset kacang hijau yang menunjukkan MAPE yang dihasilkan tinggi mayoritas antara rentang 80 sampai dengan 3500, kecuali untuk metode ERNN dengan learning rate 0.1 dan 0.2, yakni secara berturut-turut 3.3610 dan 3.6344. MAPE untuk penerapan ERNN dan BPNN fluktuatif turun naik, sedangkan untuk penerapan ES menunjukkan nilai MAPE mengalami penurunan jika learning rate ditingkatkan.

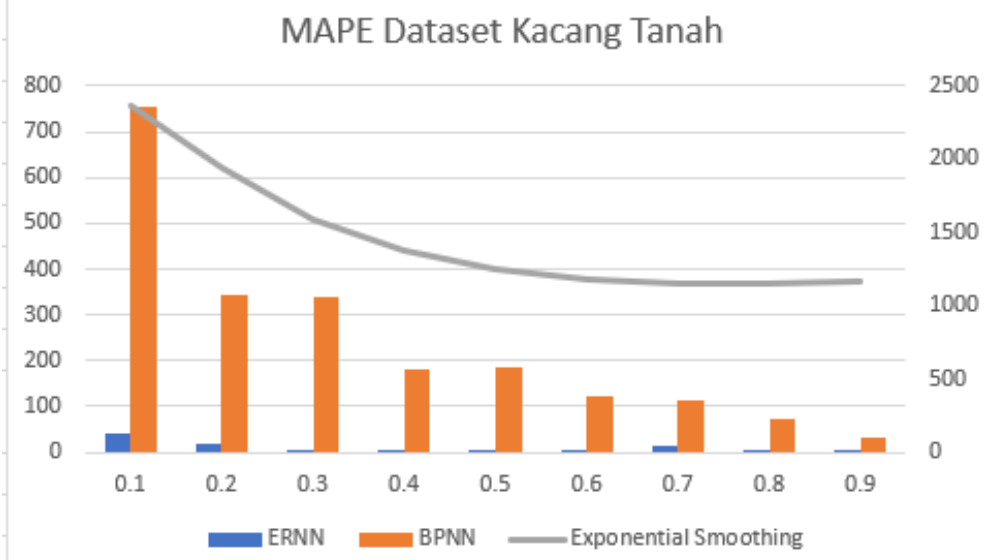

Gambar 11. MAPE untuk Dataset Kacang Tanah 
Gambar 11 menunjukkan MAPE untuk metode ERNN yakni pada rentang 0.7416 sampai dengan 39.3743 relatif lebih kecil dibandingkan dua metode lainnya, yakni pada rentang 31.57089 sampai dengan 2371.8561. Metode ERNN menunjukkan penurunan MAPE untuk learning rate dari 0.1 sampai dengan 0.5, kemudian menunjukkan peningkatan ketika learning rate ditingkatkan menjadi 0.6 sampai dengan 0.9. Sedangkan kedua metode yang lain menunjukkan peningkatan MAPE jika learning rate ditingkatkan.

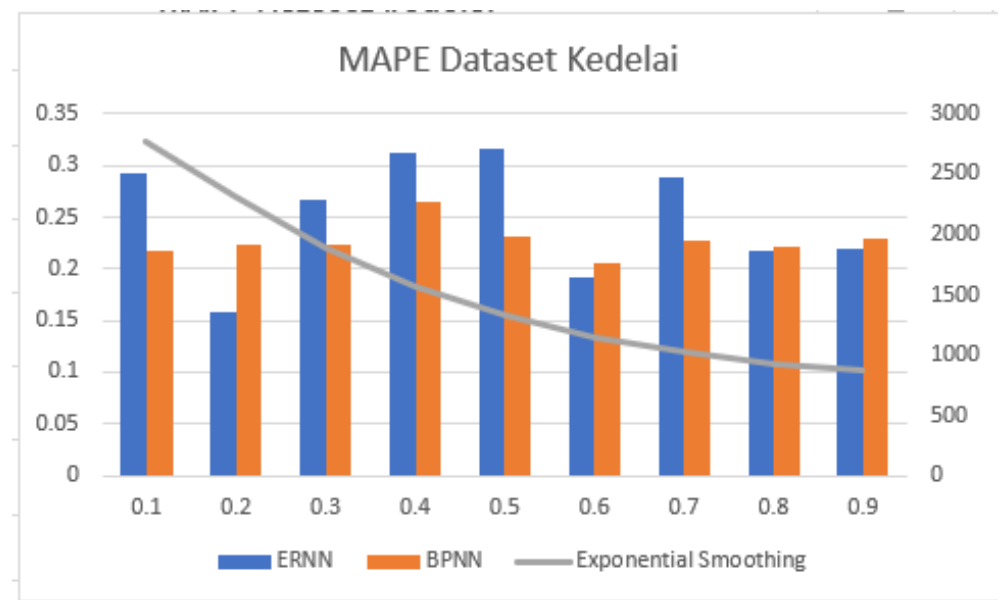

Gambar 12. MAPE untuk Dataset Kedelai

Gambar 12 menunjukkan MAPE terkecil diperoleh dari penerapan metode ERNN dengan learning rate 0.2, yakni 0.1573. Sedangkan MAPE terbesar diperoleh dari penerapan metode ES dengan learning rate 0.1, yakni 2771.1408. Gambar 12 juga menunjukkan MAPE hasil penerapan ERNN dan BPNN fluktuatif naik turun, tetapi hasil penerapan ES MAPE menunjukkan penurunan jika learning rate ditingkatkan.

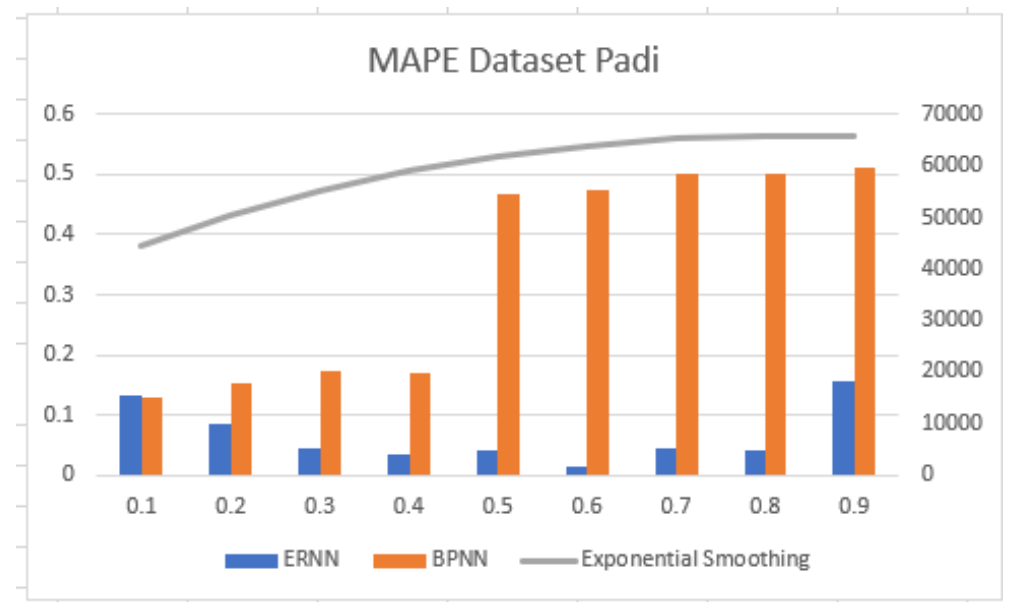

Gambar 13. MAPE untuk Dataset Padi 
Gambar 13 menunjukkan bahwa MAPE hasil penerapan metode ERNN merupakan MAPE terkecil, yakni 0.0151 pada saat learning rate 0.6. Dibandingkan dengan ES dimana MAPEnya pada rentang 44357.4931sampai dengan 65858.5040, MAPE hasil penerapan BPNN relatif sama kecilnya dengan hasil ERNN tetapi meningkat cukup banyak saat learning rate dinaikkan menjadi 0.5. MAPE hasil penerapan ERNN terlihat naik turun, sedangkan untuk kedua metode yang lain MAPE mengalami peningkatan seiring peningkatan learning rate.

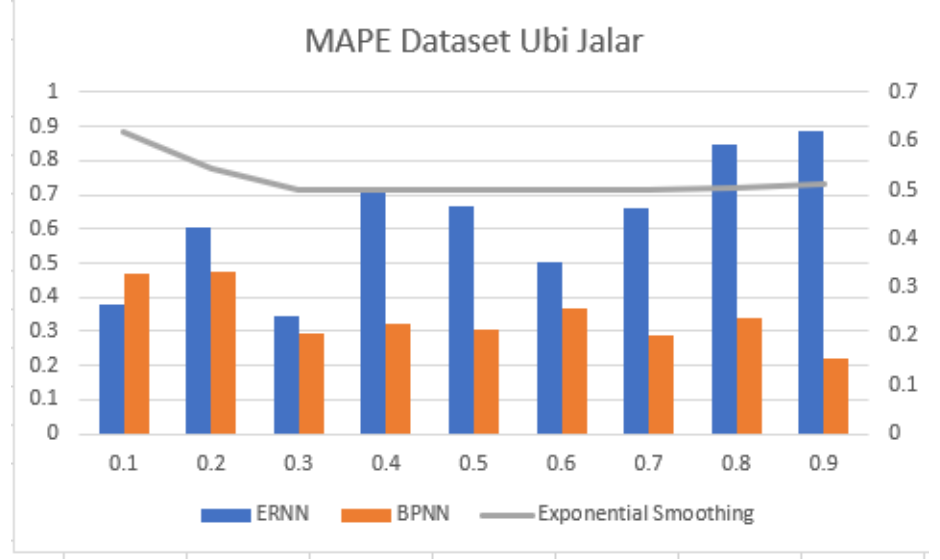

Gambar 14. MAPE untuk Dataset Ubi Jalar

Gambar 14 menunjukkan bahwa MAPE untuk hasil penerapan ketiga metode pada dataset ubi jalar relatif kecil, yakni kurang dari 1. Walaupun MAPE terkecil adalah hasil penerapan metode BPNN dengan learning rate 0.9, yakni 0.2198. Gambar 14 juga menunjukkan jika learning rate ditingkatkan maka MAPE hasil penerapan ERNN semakin meningkat, MAPE hasil penerapan BPNN semakin menurun, dan MAPE hasil penerapan ES walaupun mengalami naik turun tetapi relatif stabil pada kisaran angka 0.5 .

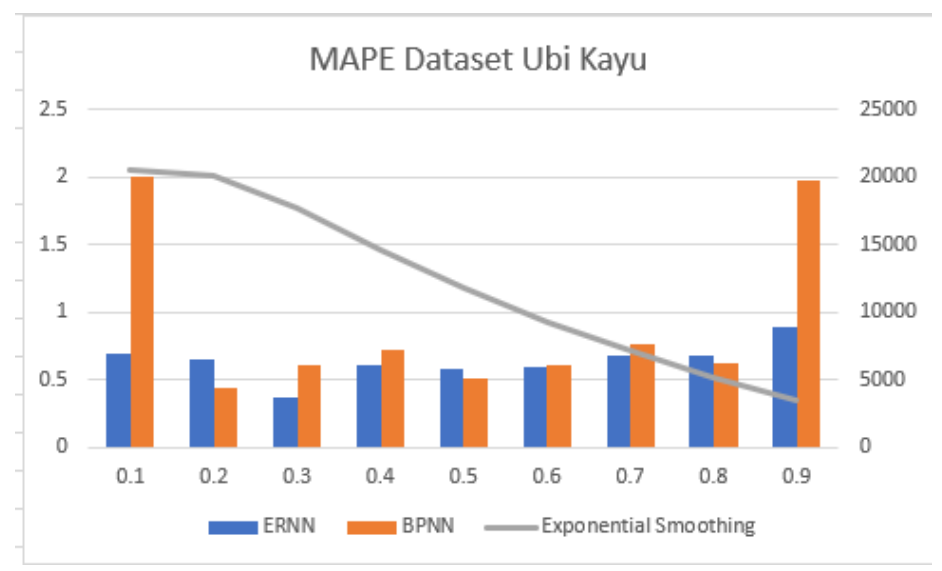

Gambar 15. MAPE untuk Dataset Ubi Kayu 
Gambar 15 menunjukkan bahwa jika learning rate ditingkatkan maka MAPE dari hasil penerapan ERNN dan BPNN naik turun. Meskipun MAPE hasil penerapan ES mengalami penurunan, tetapi tetap merupakan MAPE bernilai besar karena berada pada rentang 3519.0721 sampai dengan 20557.5900. MAPE terkecil adalah hasil penetapan metode ERNN dengan learning rate 0.3, yakni 0.3749 .

Guna melihat hasil penerapan ketiga metode, maka diambil MAPE minimum dari setiap metode pada setiap dataset yang disajikan pada Gambar 16.

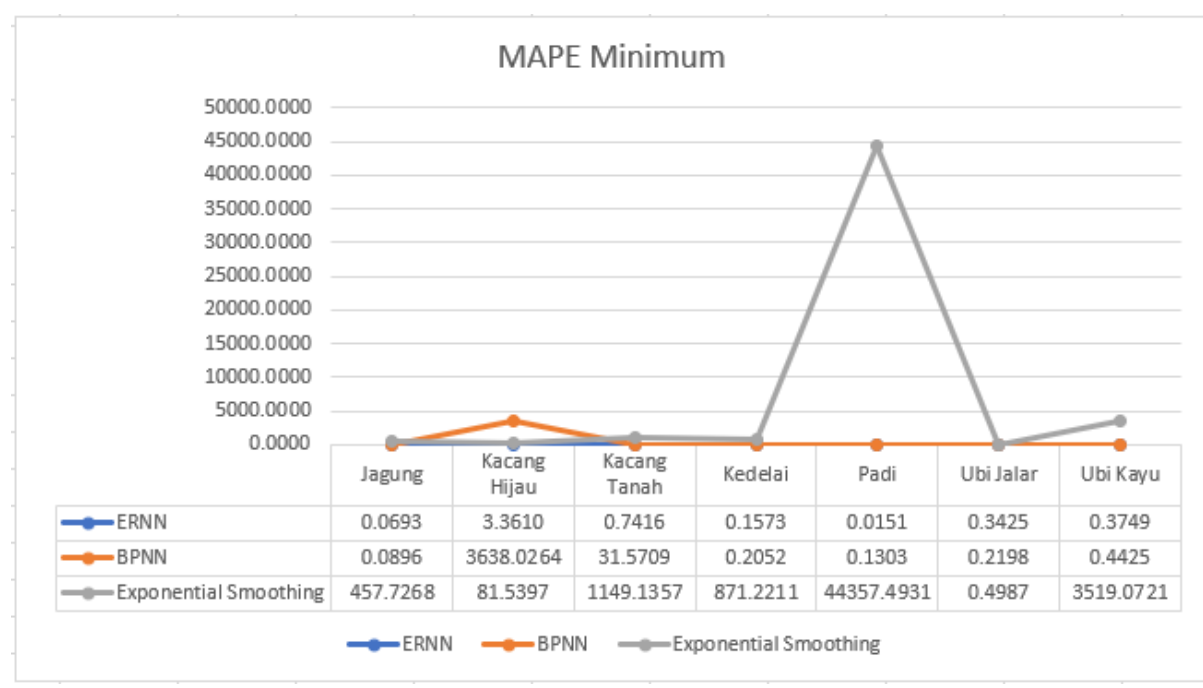

Gambar 16. MAPE Minimum

Gambar 16 menunjukkan bahwa metode ERNN menghasilkan MAPE terkecil pada enam dari tujuh dataset yang ada. Walaupun pada dataset ubi jalar, MAPE terkecil diperoleh dari hasil penerapan BPNN, yakni 0.21978, tetapi MAPE yang diperoleh dari hasil penerapan ERNN tidak berbeda jauh, yakni 0.3425. Sedangkan hasil MAPE paling besar dihasilkan dari penerapan ES. Gambar 16 juga menunjukkan penerapan BPNN untuk jumlah dataset yang lebih sedikit, yakni dataset kacang hijau memberikan MAPE yang besar.

Berikut adalah hasil keterkaitan penelitian ini dengan beberapa penelitian terdahulu yang menjadi referensi penelitian ini.

1. Hasil penelitian ini menunjukkan bahwa mayoritas penerapan ketiga metode mampu mengenali pola pada ketujuh dataset sesuai dengan penelitian terdahulu. 
2. Hasil penelitian ini sejalan dengan penelitian yang dilakukan oleh Zhang, et al (2013) dengan hasil MAPE ERNN lebih bagus dibandingkan BPNN.

3. Jumlah data latih pada dataset kacang hijau yang signifikan mempengaruhi MAPE pada penerapan metode BPNN sejalan dengan hasil penelitian oleh Nugraha, Santoso, dan Suselo (2013).

\section{SIMPULAN}

Berdasarkan uraian pada bagian hasil dan pembahasan terlihat bahwa metode ERNN menghasilkan nilai MAPE yang kecil dan stabil untuk ketujuh dataset dibandingkan dengan nilai MAPE yang dihasilkan oleh metode BPNN dan ES. Oleh karena itu, dapat dikatakan bahwa metode ERNN lebih baik dibandingkan BPNN dan ES untuk meramalkan data produksi tanaman palawija. Dengan kata lain, performa metode ERNN tidak bergantung pada dataset yang diuji.

\section{UCAPAN TERIMA KASIH}

Penulis mengucapkan terima kasih kepada Politeknik Negeri Tanah Laut atas bantuan biaya pada skema Penelitian Dosen Dana DIPA Tahun Anggaran 2020 .

\section{DAFTAR PUSTAKA}

Abraham, B., \& Ledolter, J. (2005). Statistical methods for forecasting. New Jersey: Wiley-Interscience.

Afrianty, I., et al. (2018). Penerapan jaringan syaraf tiruan Elman Recurrent Neural Network untuk prediksi penjualan pilus. Seminar Nasional Teknologi Informasi, Komunikasi, dan Industri (SNTIKI-10). Pekanbaru: UIN Sultan Syarif Kasim Riau.

Aktual kalsel. (2019). Satu prioritasi pembangunan di Tanah Laut. Retrieved September 1, 2020, from http://aktualkalsel.com/2019/09/23/sektorpertanian-merupakan-salah-satu-prioritas-pembangunan-di-tanah-laut/.

BPS Kabupaten Tanah Laut. (2020). Tanaman pangan. Retrieved September 1, 2020, from http://tanahlautkab.bps.go.id.

Cynthia, E.P., et al. (2019). Penerapan metode elman recurrent neural network (ERNN) untuk peramalan penjualan. Journal of Education Informatic Technology and Science (JeITS), 1(2), 49-61.

Nugraha, K. A., Santoso, A. J., \& Suselo, T. (2013). Algoritma backpropagation pada jaringan saraf tiruan untuk pengenalan pola wayang kulit. Seminar 
Nasional Informatika 2013 (semnas IF 2013). Yogyakarta: UPN Veteran Yogyakarta.

Apriliyani, N., Rhomadhona, H., \& Permadi, J. (2018). Aplikasi peramalan jumlah siswa sekolah dasar di kabupaten Tanah Laut menggunakan metode holt's double exponential smoothing. Jurnal Sustainable: Jurnal Hasil Penelitian dan Industri Terapan, 7(2), 64-69. https://doi.org/10.31629/sustainable.v7i2.623.

Radjabaycolle, J., \& Pulungan, R. (2016). Prediksi penggunaan bandwidth menggunakan elman recurrent neural network. Barekeng Jurnal Ilmu Matematika dan Terapan, 10(2), 127-135.

Safitri, T., Dwidayati, N., \& Sugiman. (2017). Perbandingan peramalan menggunakan metode exponential smoothing holt-winters dan ARIMA. UNNES Journal of Mathematics, 6(1), 48-58.

Salman, A.G., \& Prasetio, Y.L. (2011). Implementasi jaringan syaraf tiruan recurrent menggunakan gradient descent adaptive learning rate and momentum untuk pendugaan curah hujan. ComTech: Computer, Mathematics and Engineering Applications, 2(1), 23-35.

Sihabuddin, A., Rosadi, D., \& Utami, S. (2017). An empirical comparative forecast accuracy of exponential smoothing and nonlinear autoregressive models on six major rates. International Journal of Computer Science and Information Security (IJCSIS), 15(1), 670-672.

Suryani, I., \& Wahono, R. S. (2015). Penerapan exponential smoothing untuk transformasi data dalam meningkatkan akurasi neural network pada prediksi harga emas. Journal of Intelligent Systems, 1(2), 67-75.

Wanto, A., \& Windarto, A. P. (2017). Analisis prediksi indeks harga konsumen berdasarkan kelompok kesehatan dengan menggunakan metode backpropagation. Sinkron Publikasi Jurnal \& Penelitian Teknik Informatika, 2(2), 37-43.

Wisesa, L. (2018). Produksi pertanian Indonesia BPS 1993-2015 produksi beberapa komoditi pertanian dalam ton. Retrieved August 1, 2020 from www.kaggle.com

Wong, K., et al. (2019). Prediksi tingkat inflasi dengan menggunakan metode backpropagation neural network. Sains, Aplikasi, Komputasi dan Teknologi Informasi, 1(2), 8-13.

Zhang, X., et al. (2013). Comparative study of four time series methods in forecasting typhoid fever incidence in China. PLoS ONE, 8(5). https://doi.org/10.1371/journal.pone.0063116. 